Bacharach, V. R., \& Baumeister, A. A. (2003). Child care and severe externalizing behavior in kindergarten children. Journal of Applied Developmental Psychology, 23(5): 527-537. (Jan 2003) Published by Elsevier (ISSN: 18737900). DOI:10.1016/S0193-3973(02)00140-5

\title{
Child care and severe externalizing behavior in kindergarten children
}

Verne R. Bacharach and Alfred A. Baumeister

\begin{abstract}
Data from a large representative sample of American kindergarten children were used to examine the relationship between prekindergarten child care arrangements and the frequency of severe externalizing behaviors among these children. Compared to parental care children, there was no increase in relative risk of severe externalizing behaviors for nonrelative and center care children. Head Start and relative care were associated with an increase in the relative risk of behavior problems; however, it appears that the increases in these care settings were the result of selection factors rather than experience in the settings. Public policy implications were discussed.
\end{abstract}




\section{INTRODUCTION}

Currently, over $80 \%$ of the nation's children have been or are currently enrolled in some type of regular nonparental child care prior to kindergarten (West, Denton, \& Germino-Hausken, 1999). Because of the increase in incidence and prevalence of early nonparental child care, influence of this type of experience on children's behavior in kindergarten has become a source of concern to parents, researchers, and policy makers (Peisner-Feinberg et al., 2001).

Kindergarten traditionally represents an educational milestone in children's lives (Lloyd; Pianta and Ramey). It is important, therefore, to understand factors that might contribute to readiness for kindergarten. In particular, type and quantity of child care may be associated with children's readiness for kindergarten especially their behavioral preparedness (Haskins; Howes and Schwartz).

Perhaps the most important function of kindergarten is to socialize children to the classroom setting. Children obviously must learn to sit still, cooperate with teachers and other children, pay attention to instruction, and engage in other social behaviors that promote learning. Children with externalizing behaviors1 may be disadvantaged compared to other children in acquiring adaptive classroom social skills (Teo, Carlson, Mathieu, Egeland, \& Sroufe, 1996). A growing body of evidence links externalizing behaviors in 4- to 5-year-olds to prekindergarten child care (Bates; Belsky; Belsky; Belsky; DiLalla and Violato). The purpose of the present paper is to examine and describe the relation between antisocial behaviors of kindergarten children and their prior experience with different models of prekindergarten care.

The best evidence for a connection between externalizing behaviors of kindergarten-aged children and care giving comes from analyses of data collected as a part of the NICHD Study of Early Child Care. Reports based on this longitudinal data set have shown a positive relationship between the quantity of nonparental care and externalizing behavior problems in kindergartenaged children (Belsky; Belsky and Vandell). Results from the Study of Early Child Care are based on a carefully selected cohort of 1364 children (some specific analyses have smaller N's because there is not a complete data set for all children). A major interpretative problem associated with the NICHD study is that the cohort is not a population-based sample. Given the difficulty of creating a population-based sample, it is not surprising that most, if not all, of our information concerning a correlation between conduct problems in kindergarten children and prekindergarten child care is based on convenience samples (e.g., Schweinhart \& Weikart, 1997). Even though these types of studies contribute to our understanding of early childhood behavior disorders and their effects on kindergarten readiness, generalizing from these studies to the general population of kindergarten children is problematic (Burchinal \& Nelson, 2000).

Although there is some indication that type of prekindergarten care is related to behavior problems in young children, there is also contrary evidence suggesting that care arrangements are either unrelated to behavior problems (Blau; Erel; Infant and Lamb) or that nonparental care can actually reduce behavior problems in young children (Denham; Field and Field). In this regard, generalizing across studies is difficult because of different sample types, variations in research designs, and discrepancies in the ways that care arrangements and behavior problems have been operationally defined. At present, there is no definitive answer to the 
question as to whether there is a relationship between prekindergarten care arrangements and risk of subsequent behavior disorders among children in kindergarten.

Research literature in this area is also constrained by other factors. Most studies of child care effects on subsequent behavior problems in school settings explore the influence of center care (e.g., Creps; Denham and Peisner). This is a problem for several reasons. Center care is but one category of child care arrangement used by parents, often in conjunction with other types. Hours of attendance in other care arrangements is not likely to be independent of hours in center care, and choice of day care arrangement is likely to be confounded with family selection factors - factors that influence the type of care arrangement selected by a family. These problems make it difficult to distinguish center care effects from influences associated with other care arrangements.

One purpose of the present study is to address some of the concerns noted above by analyzing data from a very large population-based sample of kindergarten children. The fact that the sample is population-based has two important implications. First, representativeness of the data is assured. Therefore, analyses derived from the population-based sample paint a picture, a demographic snapshot, of the present state of affairs regarding the emergence of behavior problems in kindergarten children and their previous child care arrangements. Second, such data invite epidemiological analyses similar to those used by previous authors (e.g., Cooper; Hofferth and Rimm). This type of statistical approach focuses on relative risk (RR) as opposed to crude rates and yields statistical indices, particularly effect size, that are readily interpretable and have pragmatic value in applied contexts where researchers and policy decision makers are trying to assess effects of social policy on relatively low-frequency outcomes. For example, estimates of the RR of severe externalizing behavior problems can be computed for different types of prekindergarten care arrangements relative to parental care.

The large size of the sample used in the present analyses also has important implications for disaggregating effects of specific care arrangements on behavior of kindergarten children. In the general population, there are not likely to be many children who have had only one type of prekindergarten care (Hofferth et al., 1998). A large sample from the general population is required to obtain adequate sample sizes in these groups to assure statistical stability when examining the impact of different care arrangements on behavior problems. Sample size is also important because only a small fraction of all children exhibit unusual or extreme behavior disturbances. Unless children with these problems are over-sampled, a population-based sample must be large enough to capture a sufficient number of children for suitable statistical analyses.

The present analyses employ data from the Early Childhood Longitudinal Study, Kindergarten Class of 1998-99 (See ECLS-K; National Center for Educational Statistics, 2000 for details). The ECLS-K data derive from a representative sample of 22,782 American kindergarten children. The intent of the our analyses is to describe the present composition of different prekindergarten care arrangements, to determine whether any of these arrangements is associated with an increase in the risk of extreme externalizing behavior in kindergarten 
classrooms, and if such risks exist to explore the possibility that the increase is related to quantity of child care exposure.

\section{METHOD}

\section{Participants}

For purposes of the present analyses, we selected children who were without disabilities and whose primary spoken language was English. The sample included 13,288 children. Forty-nine percent were males, 65\% White, 17\% Black, and 11\% Hispanic. On average, they were 68.42 months of age $(S D .=4.33)$ at the time of assessment.

\section{Analytic approach}

The dependent variable in these analyses was a score derived from the externalizing problem behavior subscale of a social behavior rating scale filled out for each child by the kindergarten teacher during the Fall term of the child's first year in kindergarten. Five behavioral categories are sampled by the subscale (child argues, child fights, child gets angry, child acts impulsively, and child disturbs class activities). For each behavioral category, the teacher indicated the frequency of occurrence on a four-item scale with 1 indicating "never", 2 "sometimes", 3 "often", and 4 "very often". Each child was assigned a mean externalizing behavior score computed by averaging across category ratings. The mean rating for all children for whom these values were available was $1.7(\mathrm{SD} .=0.07, \mathrm{~N}=12,804)$. The split half reliability from the complete sample was 0.90 (West et al., 1999).

For purposes of risk analysis, we identified those children whose externalizing behavior scores were $2 \mathrm{SD}$. above the mean, categorizing these as children with severe behavior problems. Other researchers have similarly categorized children, although the usual procedure is to identify children as behavior problems when their externalizing behavior scores exceed approximately 1 SD. above the mean (Belsky; Cooper and Vandell). The rationale for selecting 2 SD. as a cutoff is based on the assumption that all children are likely to exhibit one or more behavior disturbances over the course of several months; however, from an educational perspective, those who exhibit extreme and enduring maladaptive behaviors on a regular basis present the most serious disciplinary problems and are at the greatest educational risk.

The externalizing behavior scores of the children were used to compute estimated RR. Except where indicated, the estimated RR of behavior problems was determined by dividing the odds of behavior problems among children who have had only one of a specified type of nonparental care (e.g., Head Start) by odds of behavior problems among children who have had no nonparental care prior to kindergarten (parental care children). In this case, odds ratios can be interpreted as estimates of RR (Ahlbom and Sahai). The 95\% confidence interval associated with each risk estimate will also be reported. 


\section{RESULTS}

\section{Child care demographics}

Approximately $84 \%$ of the parents in the entire sample reported that their children had some type of nonparental care prior to kindergarten. Of the children for whom there was a complete set of data regarding care arrangements, $48 \%$ of the children had only one type of prekindergarten, nonparental care. The remaining children had two or more types of nonparental care prior to kindergarten.

Of the different types of care arrangements available to children, the most popular was center care (excluding Head Start). Sixty-three percent of parents reported that their child had had some type of center care prior to kindergarten. Approximately $12 \%$ of the children had been enrolled in Head Start or Early Head Start. The percentages for relative and nonrelative care were $40 \%$ and $35 \%$, respectively.

Large percentages of children had experiences with nonparental care within the first 6 months of birth. This included $91 \%$ of children who received relative care, $88 \%$ with nonrelative care, and $82 \%$ who had some type of prekindergarten center care. Seventy-eight percent of children who at some time had been enrolled in Head Start or Early Head Start began their Head Start experience during their first 6 months of life.

\section{Demographics of externalizing behavior problems}

Of the children in the present study, $4.7 \%$ were classified as having severe behavior problems. Boys were 2.7 times more likely than girls to be so classified; $\mathrm{Cl}_{95 \%}=2.28-3.27$. Black children were 1.9 times more likely than white children to have been identified as a severe behavior problem, $\mathrm{Cl}_{95 \%}=1.58-2.33$. Children whose ethnic identification was Hispanic were no more likely than white children to exhibit externalizing behavior problems $\left(\mathrm{Cl}_{95 \%}=0.69-1.57\right)$.

\section{Relationship between extreme externalizing behavior and prekindergarten care arrangements}

These risk analyses are based on 1190 children (parental care children) who were reported to have had no prekindergarten nonparental care and for whom there were data concerning externalizing behavior problems. The odds of behavior problems among these children was used as the denominator in calculation of the odds ratios that follow. With respect to each care class, reported risks are based on data obtained from those children in each category who had no other variety of care prior to kindergarten. For example, there was a subsample of children who received nonrelative care but had no other type of nonparental care prior to kindergarten. The RR associated with nonrelative care is based on the frequency of occurrence of behavior problems in this particular subsample. 
Four different nonparental care arrangements were examined: relative care, nonrelative care, center care excluding Head Start, and Head Start. Only Head Start and relative care were associated with an increase in estimated RR of extreme behavior problems. In the case of Head Start, children in these programs were 2.65 times more likely to exhibit extreme behavior problem scores than the parental care children, CI95\%=1.53-4.62. Relative care was associated with an RR of $2.71, \mathrm{Cl} 95 \%=1.45-5.08$. The comparable figures for nonrelative and center care were $1.33(\mathrm{Cl} 95 \%=0.54-3.2)$ and $1.25(\mathrm{CI} 195 \%=0.80-1.94)$, respectively.

There are at least two possible explanations for the increase in these RR. The increments could be due to experiences children have while in Head Start or in relative care, or they could be the result of other factors associated with these care arrangements but not related directly to care experience. An examination of dose-response rates for each of the care types might provide evidence that could be used to eliminate the former hypothesis as an explanatory candidate (Belsky et al., 2001). If experience in a particular care setting is causing an increase in behavior problems, then the frequency of these problems should increase as a function of quantity of care. Absence of a relation between time spent in care and frequency of behavior problems could be taken as evidence against the causal hypothesis. To explore the possibility that there is a relation between quantity of care experience and severe behavior problems, we examined frequency of occurrence of behavior problems as a function of time spent in each of the relevant care types.

Data concerning quantity of Head Start and relative care in the ECLS-K data set were limited to time spent in these care types during the year immediately preceding the kindergarten year. For Head Start, information was available for each child regarding the number of hours each week spent at a program site. For relative care, data concerning months in care were also available. We analyzed hours each week spent in relative care only for those children who had 9-12 months of relative care.

Because the hour-per-week values were distributed multimodally (they tended to clump around values like 20,30, and 40), we sorted hours-per-week into three categories and performed Chisquare analyses examining the relationship between these categories and number of children with extreme externalizing behavior scores. The first category included children with $15 \mathrm{~h}$ or less per week in care. Hours in the second category ranged from 16 to $30 \mathrm{~h}$. The remaining hours were placed in the third category. On average, children spent $23.41 \mathrm{~h}$ each week in Head Start programs $(S D .=10.81)$. They were in relative care an average of $25.15 \mathrm{~h}$ each week $(\mathrm{SD} .=15.31)$.

The results of the Chi-square analyses suggest that quantity of care is not related to the likelihood of severe externalizing behaviors in kindergarten children. Neither the Head Start nor the relative care values were statistically significant, $x 2(2, N=1626)=1.30, p=.52 ; x 2(2$, $\mathrm{N}=2978)=0.42, \mathrm{p}=.81$, respectively. These results are not consistent with dose-response rates reported by Belsky et al. (2001). 
There is an additional way nonparental care might be related to severe externalizing behavior among kindergarten children. Because $50 \%$ or more of children who experienced some type of nonparental care had more than one type, it is possible that the number of different care arrangements, regardless of type, might be related to the risk of developing an externalizing behavior problem. We examined the proportion of children with externalizing behavior problems as a function of number of different types of care experienced by each child. As number of care arrangements increased, there was an increase in the proportion of children with externalizing behavior problems, $\mathrm{X} 2(2, \mathrm{~N}=7124)=7.34, \mathrm{p}=.03$. Four and one-half percent of the children with one care arrangement displayed behavior problems. This value increased to $5.1 \%$ for children with two care experiences and $6.7 \%$ for children with three or more such experiences. Of course, number of care arrangements might be correlated with total time in nonparental care. Unfortunately, the ECLS-K data set does not include data needed to explore this possibility.

\section{DISCUSSION}

Little evidence was found that type or quantity of nonparental prekindergarten care has an influence on severe externalizing behavior in kindergarten children relative to the likelihood of these problems in parental care children. Although risk of extreme externalizing behaviors was greater for Head Start and relative care children compared to parental care children, there was no confirmation that experience in these nonparental arrangements was related to behavior problems. Rather, apparently some type of selection factor associated with externalizing behaviors seems to influence the selection of nonparental care type. Previous research has identified some of the factors associated with care selection (Burchinal; Hofferth; Lamb; Peyton; Singer and Vandell).

It could be argued that number of different prekindergarten care arrangements contributed to an increase in behavior problems. However, it is just as likely that number of care arrangements is the product of the behavior. The directionality problem is obvious, and we think it is a fundamental dilemma with much of the reported research. Even in those studies in which an association has been found between duration of care and behavior problems, the directionality issue remains: is the increase in behavior problems due to an increase in hours of care or the other way around? Unfortunately, longitudinal studies are of little help in this matter, in part because variability in care arrangements and variability in behavior are both likely to be related to genetic variability and/or to family selection factors (Burchinal; Cleveland and Collins).

There could be evidence from randomized trial studies that might clarify the issue. These types of studies, however, have been primarily concerned with center care effects on developmental outcomes and have not been population-based; instead, they usually focus on special populations of children (e.g., Haskins and Schweinhart). Further, the results of these studies are wildly inconsistent. Haskins (1985) reported an increase in school age behavior problems among center care children compared to a control group of children who took part in the Abecedarian Project. In contrast, intensive center care had no effect on school-related behavior problems of children who had been enrolled in another center care randomized trial (Infant Health and Development Program, 1997). Clarke and Campbell (1998) examining criminal 
records of 18-year-olds who as children had also been involved in the Abecedarian Project found no difference in incidence of criminal behavior between center care and control children. Reports from the Perry Pre-school project indicated that type of preschool care had no statistically significant effects on school misbehavior (Schweinhart, Barnes, \& Weikart, 1993) but had large effects on subsequent criminal behavior in which adults with center care had lower rates of criminal activity (Schweinhart \& Weikart, 1997). The obvious solution to this interpretive dilemma would require a controlled randomized study. However, it is highly unlikely that randomized trials involving different forms of care could be carried out.

The results of our analyses suggest that severe externalizing behavior problems in young children are not related to experiences that they have in prekindergarten care. The association between care type and behavior problems seems to be related to type of care selected by parents rather than time in care. The fact that time in care was not associated with an increase in behavior problems is inconsistent with findings reported by Belsky et al. (2001). The inconsistency might be related to different samples used in the two studies. Whereas Belsky et al. report results from a convenience sample of children, our results are based on a larger and nationally representative sample of children. There are other methodological details, for example, how children with behavior problems were identified, that could have contributed to the different results. Further research is needed to resolve this issue.

Many have commented on the policy implications of early child care research (e.g., Belsky and Lloyd). At least three policy implications follow from the findings reported here. First, parents do not need to be concerned with the type of care or the amount of care that they select for their toddlers. Within normal limits, severe externalizing behavior of their children will not be influenced by these factors. Second, to the extent that government agencies desire to fund preschool care opportunities, there is no reason from a behavioral perspective to funnel the funding to any particular model of care arrangement. Given this fact, probably the most efficient way to fund preschool care would be to provide families with financial help and permit them to chose the care arrangements that best suit their needs.

Third, approximately 50 children out of 1000 have severe externalizing behavior problems. This means that a kindergarten teacher in an average kindergarten class can expect to have one or two children presenting with these problems. Because of the wide range of putative etiologies associated with severe behavior problems and because of the small number of children displaying these problems, individualized behavior management programs within the classroom can probably best and most efficiently serve them. The classroom is a good setting for the implementation of behavior management programs because of its relatively restricted environment and because teachers generally have tight behavioral control of the children.

These considerations suggest that that the best policy concerning preschool care arrangements would be an unrestricted policy regarding type of care. That is, allow parents to make their own care decisions, and let them know that their decisions are not likely to do irreparable damage to their children. There is no evidence that early nonmaternal care produces long-term detriments in social development. This conclusion is similar to one reached by Scarr (1997). 


\section{Methodological considerations}

The odds ratios reported in this paper were computed using the odds of behavior problems among parental care children in the denominator. Other denominators are possible. For example, we could have computed the risk of behavior problems by including the odds of behavior problems for all children regardless of care arrangement in the denominator. Selection of denominator odds can be a controversial issue. In the present case, given the historical and cultural emphasis placed on parental care in American society and given theory on child care effects (Bowlby, 1958), it seemed logical to use parental care odds as the baseline for comparison.

Precaution should be taken when comparing results of care arrangement studies to examine the source of information about behavior problems. For example, in the present case, the children's kindergarten teachers conducted the behavioral assessments. In the case of most of the Early Child Care Study, the reported behavioral data are from parents' assessments (e.g., NICHD Early Childhood Care Research Network, 2001). There is reason to think that these may not be comparable data sets. There is evidence that teacher-parent behavioral ratings are not highly correlated (Eisenberg; Fagan; Vandell and West) possibly due to children exhibiting different types of behaviors in different social settings (Harris, 1995).

With these considerations in mind, the present analyses clearly demonstrate that prekindergarten care arrangements do not seem to be directly related to severe externalizing behavior problems in kindergarten children. In fact, it seems likely to us that children's prekindergarten behavior is influencing the type, and the number of different types, of care selected for the children.

\section{ACKNOWLEDGEMENTS}

The authors would like to thank Michael Furr for his assistance with the original manuscript.

\section{NOTE}

1. The term "externalizing behavior", as employed here, is consistent with current usage in the field of psychopathology, referring to a broad assortment of disorders, including aggression, acting out, oppositional behavior, and hyperactivity (Merrell, 1999). 


\section{REFERENCES}

Ahlbom, 1993. A. Ahlbom, Biostatistics for epidemiologists., Lewis, Ann Arbor, MI (1993).

Bates et al., 1994. J. Bates, D. Marvinney, T. Kelly, K. Dodge, D. Bennett and G. Pettit , Child care history and kindergarten adjustment. Developmental Psychology 30 (1994), pp. 690-700.

Belsky, 1988. J. Belsky, The "effects" of infant day care reconsidered. Early Childhood Research Quarterly 3 (1988), pp. 235-272.

Belsky, 1999. J. Belsky, Quantity of nonmaternal care and boys' problem behavior/adjustment at 3 and 5: exploring the mediating role of parenting. Psychiatry: Interpersonal and Biological Processes 62 (1999), pp. 1-20. View Record in Scopus | Cited By in Scopus (21)

Belsky et al., 2001. J. Belsky, M. Weinraub, M. Owen and J.F. Kelly, Further explorations of the detected effects of quantity of early child care on socioemotional adjustment. In: Paper presented at the meeting of the Society for Research in Child Development, Minneapolis, MN (2001 April).

Blau, 1999. D.M. Blau, The effect of child care characteristics on child development. Journal of Human Resources 34 (1999), pp. 786-822.

Bowlby, 1958. J. Bowlby, The nature of child's tie to his mother. International Journal of Psychoanalysis 39 (1958), pp. 350-373.

Burchinal and Nelson, 2000. M.R. Burchinal and L. Nelson, Family selection and child care experiences: implications for studies of child outcomes. Early Childhood Research Quarterly 15 (2000), pp. 385-411.

Clarke and Campbell, 1998. S.H. Clarke and F.A. Campbell , Can intervention early prevent crime later? The Abecedarian Project compared with other programs. Early Childhood Research Quarterly 13 (1998), pp. 319-343.

Cleveland et al., 2000. H.H. Cleveland, R.P. Wiebe, E.J.C.G. van den Oord and D.C. Rowe, Behavior problems among children from different family structures: the influence of genetic selfselection. Child Development 71 (2000), pp. 733-751.

Collins et al., 2000. W.A. Collins, E. Maccoby, L. Steinberg, E.M. Hetherington and M. Bornstein , Contemporary research on parenting: the case for nature and nurture. American Psychologist 55 (2000), pp. 218-232.

Cooper and Farran, 1988. D.H. Cooper and D.C. Farran, Behavioral risk factors in kindergarten. Early Childhood Research Quarterly 3 (1988), pp. 1-19.

Creps and Vernon-Feagans, 1999. C.L. Creps and L. Vernon-Feagans, Preschools' social behavior in day care links with entering day care in the first year. Journal of Applied Developmental Psychology 20 (1999), pp. 461-479. 
Denham and Burton, 1996. S.A. Denham and R. Burton, A social-emotional intervention for atrisk 4-year-olds. Journal of School Psychology 34 (1996), pp. 225-245.

DiLalla, 1998. L.F. DiLalla, Daycare, child, and family influences on preschoolers' social behaviors in a peer play setting. Child Study Journal 28 (1998), pp. 223-244.

Eisenberg et al., 2001. N. Eisenberg, A. Cumberland, T.L. Spinrad, R.A. Fabes, S.A. Shepard, M. Reiser, B.C. Murphy, S.H. Losoya and I.K. Guthrie, The relations of regulation and emotionality to children's externalizing and internalizing problem behavior. Child Development 72 (2001), pp. 1112-1134.

Erel et al., 2000. O. Erel, Y. Oberman and N. Yirmiya, Maternal versus nonmaternal care and seven domains of children's development. Psychological Bulletin 126 (2000), pp. 727-747.

Fagan and Fantuzzo, 1999. J. Fagan and J.W. Fantuzzo, Multirater congruence on the social skills rating system: mother, father, and teacher assessments of urban Head Start children's social competencies. Early Childhood Research Quarterly 14 (1999), pp. 229-242.

Field, 1991. T. Field, Quality infant day care and grade school behavior and performance. Child Development 62 (1991), pp. 863-870.

Field et al., 1988. T. Field, W. Masi, S. Goldstein, Perry and S. Parl , Infant day care facilitates preschool social behavior. Early Childhood Research Quarterly (1988), pp. 341-359.

Harris, 1995. J.R. Harris , Where is the child's environment? A group socialization theory of development. Psychological Review 102 (1995), pp. 458-489.

Haskins, 1985. R. Haskins, Public school aggression among children with varying day care experience. Child Development 56 (1985), pp. 689-703.

Hofferth et al., 1998. S.L. Hofferth, K.A. Shauman and R.R. Henke, Characteristics of children's early care and education programs: data from the 1995 National Household Education Survey (NCES report no. 98-12). , U.S. Department of Education, National Center for Educational Statistics, Washington, DC (1998).

Howes, 1990. C. Howes, Can the age of entry into child care and the quality of child care predict adjustment in kindergarten?. Developmental Psychology 26 (1990), pp. 292-303.

Infant Health and Development Program, 1997. Infant Health and Development Program, Results at age 8 years of early intervention for low-birth-weight premature infants. Journal of the American Medical Association 277 (1997), pp. 126-132.

Lamb, 1998. M.E. Lamb , Nonparental child care: context, quality, correlates. In: W. Damon, I.E. Sigel and K.A. Renninger, Editors, Child psychology in practice, 5th ed.Handbook of Child Psychology vol. 4, Wiley, New York (1998), pp. 73-134. 
Lamb et al., 1988. M.E. Lamb, C.P. Hwang, A. Broberg and F.L. Bookstein, The effects of out of home care on the development of social competence in Sweden: a longitudinal study. Early Childhood Research Quarterly 3 (1988), pp. 379-402.

Lloyd et al., 1999. J.W. Lloyd, D.R. Steinberg and M.K. Wilhelm-Chapin, Research on the transition to kindergarten. In: R.C. Pianta and M.J. Cox, Editors, The transition to kindergarten, Paul H. Brookes, Baltimore (1999), pp. 3-12.

Merrell, 1999. K.W. Merrell , Behavioral, social, and emotional assessment of children and adolescents. , Erlbaum, Mahwah, NJ (1999).

National Center for Educational Statistics, 2000. National Center for Educational Statistics (2000). Data files and electronic code book: ECLS-K restricted-use base year: child file, teacher file, and school file (CD-ROM). (NCES Pub. No. 2000-097). Washington DC: U.S. Department of Education, National Center for Educational Statistics.

NICHD Early Childhood Care Research Network, 2001. NICHD Early Childhood Care Research Network, Child care and children's peer interactions at 24 and 36 months: the NICHD study of early child care. Child Development 72 (2001), pp. 1478-1500.

Peisner-Feinberg and Burchinal, 1997. E. Peisner-Feinberg and M. Burchinal, Concurrent relations between child care quality and child outcomes: the study of cost, quality, and outcomes in child care center. Merrill-Palmer Quarterly 43 (1997), pp. 451-477.

Peisner-Feinberg et al., 2001. E.S. Peisner-Feinberg, M.R. Burchinal, R. Clifford, M.L. Culkins, C. Howes, S.L. Kagan and N. Yazejian, The relation of preschool child-care quality to children's cognitive and social developmental trajectories through second grade. Child Development 72 (2001), pp. 1534-1553.

Peyton et al., 2001. V. Peyton, A. Jacobs, M. O'Brien and C. Roy, Reasons for choosing child care: associations with family factors, quality, and satisfaction. Early Childhood Quarterly 16 (2001), pp. 191-208.

Pianta et al., 1999. R.C. Pianta, S.E. Rimm-Kaufman and M.J. Cox , Introduction: an ecological approach to kindergarten transitions. In: R.C. Pianta and M.J. Cox, Editors, The transition to kindergarten, Paul H. Brookes, Baltimore (1999), pp. 3-12.

Ramey and Ramey, 1999. C.T. Ramey and S.L. Ramey, Beginning school for children at risk. In: R.C. Pianta and M.J. Cox, Editors, The transition to kindergarten, Paul H. Brookes, Baltimore (1999), pp. 3-12.

Rimm-Kaufman et al., 2000. S.E. Rimm-Kaufman, R.C. Pianta and M.J. Cox , Teachers' judgments of problems in the transition to kindergarten. Early Childhood Research Quarterly 15 (2000), pp. 147-166.

Sahai and Khurshid, 1996. H. Sahai and A. Khurshid, Statistics in epidemiology: methods, techniques and applications. , CRC Press, New York (1996). 
Scarr, 1997. S. Scarr, Why child care has little impact on most children's development. Current Directions in Psychological Science 6 (1997), pp. 143-148.

Schwartz et al., 1974. J.C. Schwartz, R.G. Strickland and G. Krolick , Infant day care: behavioral effects at preschool age. Developmental Psychology 10 (1974), pp. 502-506.

Schweinhart et al., 1993. L.J. Schweinhart, H.V. Barnes and D.P. Weikart, Significant benefits: the High/Scope Perry Preschool Study through age 27. , High/Scope Press, Ypsilanti, MI (1993).

Schweinhart and Weikart, 1997. L.J. Schweinhart and D.P. Weikart, The High/Scope preschool curriculum comparison study through age 23. Early Childhood Research Quarterly 12 (1997), pp. 117-143.

Singer et al., 1998. J.D. Singer, B. Fuller, M.K. Keiley and A. Wolf , Early child-care selection: variation by geographic location, maternal characteristics, and family structure. Developmental Psychology 34 (1998), pp. 1129-1144.

Teo et al., 1996. A. Teo, E. Carlson, B.E. Mathieu and L.A. Sroufe , A prospective longitudinal study of psychosocial predictors of achievement. Journal of School Psychology 34 (1996), pp. 285-306.

Vandell et al., 2001. D. Vandell, M. Burchinal, S.L. Friedman and C.A. Brownell, Overview of early child care effects at 4.5 years. In: Paper presented at the meeting of the Society for Research in Child Development, Minneapolis, MN (2001 April).

Violato and Russell, 2000. C. Violato and C. Russell , Effects of nonmaternal care on child development: a meta-analysis of published research. In: C. Violato, E. Oddone-Paolucci and M. Genius, Editors, The changing family and child development, Ashgate, Aldershot, England (2000), pp. 268-301.

West et al., 1999. J. West, K. Denton and E. Germino-Hausken , America's kindergartners. (NCES Pub. No. 2000-070). , U.S. Department of Education, National Center for Educational Statistics, Washington, DC (1999). 